\title{
Terrestrial snail records in the loess sequence from arid Central Asia since the last deglaciation, and their paleoenvironmental significance
}

\author{
Xiulan ZonG ${ }^{1,2,3}$, JiBAo DONG ${ }^{1,2}$, PenG ChenG ${ }^{1,2}$, \\ YOUGUI SONG ${ }^{1,2}$, WeIGUO LIU ${ }^{1,2}$ \\ ${ }^{1}$ State Key Laboratory of Loess and Quaternary Geology, \\ Institute of Earth Environment, Chinese Academy of \\ Sciences, Xi'an 710061, China \\ ${ }^{2}$ CAS Center for Excellence in Quaternary Science and \\ Global Change, Xi'an 710061, China \\ ${ }^{3}$ University of Chinese Academy of Sciences, Beijing \\ 100049, China \\ *Correspondence: Jibao Dong, djb@ieecas.cn
}

A variety of proxies has been studied to document paleoclimatic changes in arid Central Asia (ACA). However, biological records, which can be directly related to climatic conditions, are still scarce in this region. Here we report a record of terrestrial snails since the last deglaciation in the loess section at Talede, Xinjiang, eastern Central Asia, comprising total counts of fossils (TCF), organic carbon isotopes $\left(\delta^{13} \mathrm{Corg}\right)$ and the loss on ignition (LOI). The record prior to the Holocene reveals rare fossils; $\delta^{13} \mathrm{C}_{\text {org }}$ was generally more positive than $-21 \%$; and LOI was relatively low. These results indicated low biomass/organic carbon content inferred as environmental conditions that were unfavorable (cold/dry) for the survival of snails. In contrast, the TCF increased abruptly during the Holocene, coincident with a prominent increase in LOI and a marked negative shift in $\delta^{13} \mathrm{C}_{\text {org }}$. From the early to late Holocene, the TCF increased to its maximum, $\delta^{13} \mathrm{C}_{\text {org }}$ became more negative and LOI remained high; these changes imply a trend towards wetter conditions during the Holocene. Overall, our study demonstrated a significant improvement in environmental conditions for snails (e.g. increased temperature and precipitation/relative humidity) during the Holocene, with optimal moisture conditions in ACA occurring the late Holocene. 